\title{
Sudden olfactory loss as an early marker of COVID-19: a nationwide Italian survey
}

\author{
Lucrezia Spadera $^{1} \cdot$ Pasquale Viola $^{2} \cdot$ Davide Pisani $^{2} \cdot$ Alfonso Scarpa $^{3}$ (D) - Donatella Malanga ${ }^{4,5}$. \\ Gerardo Sorrentino ${ }^{1}$. Enrico Madini ${ }^{6}$. Carla Laria ${ }^{7}$. Teodoro Aragona ${ }^{8}$. Gianluca Leopardi ${ }^{9}$. \\ Giandomenico Maggiore ${ }^{10} \cdot$ Marco Ciriolo $^{2} \cdot$ Luigi Boccuto $^{11,12} \cdot$ Raffaella Pizzolato $^{13} \cdot$ Ludovico Abenavoli $^{14}$. \\ Claudia Cassandro ${ }^{15}$. Massimo Ralli ${ }^{16} \cdot$ Ettore Cassandro $^{3} \cdot$ Giuseppe Chiarella $^{2}$
}

Received: 9 May 2020 / Accepted: 27 July 2020 / Published online: 4 August 2020

(c) Springer-Verlag GmbH Germany, part of Springer Nature 2020

\begin{abstract}
Purpose The presence of many asymptomatic COVID-19 cases may increase the risks of disease dissemination, mainly for physicians. There are numerous reports on the frequent findings of sudden anosmia or hyposmia, before or at the same time of the typical COVID-19 symptoms onset. The aim of this study was to verify the association of olfactory impairment and COVID-19, providing a basis for subsequent research in the field of COVID-19 clinical heterogeneity.

Methods We developed a 15-item online questionnaire on "Sudden Olfactory Loss (SOL) and COVID-19" that was administered during March 2020 to Italian general practitioners registered to a social media group.

Results One hundred and eighty responses were received. SOL was identified as a significant sign of infection in COVID-19 patients, mainly aged between 30 and 40 years, even in the absence of other symptoms. SOL was present as an initial symptom in $46.7 \%$ of subjects, and in $16.7 \%$, it was the only symptom. Among the COVID-19 confirmed cases, SOL occurred as the only symptom in $19.2 \%$ of patients.

Conclusion SOL could represent a possible early symptom in otherwise asymptomatic COVID-19 subjects. Subjects affected by SOL should be considered as potential COVID-19 cases.
\end{abstract}

Level of evidence 4.

Keywords COVID-19 $\cdot$ Anosmia $\cdot$ Hyposmia $\cdot$ Sudden olfactory loss $\cdot$ Nasal $\cdot$ Taste $\cdot$ Smell $\cdot$ Screening

\section{Introduction}

In late December 2019, the appearance of clusters of patients with pneumonia of unknown cause was reported for the first time in Wuhan, China [1]. In the first reports of this condition, the Chinese scientists identified the responsible pathogen in a novel strain of coronavirus $(\mathrm{CoV})$ found in bronchoalveolar-lavage samples of the patients affected by severe pneumonia. Next-generation sequencing analysis indicated that the unknown genome showed more than $85 \%$ identity with those of a bat SARS-like CoV [2]. In January 2020, the Chinese authorities shared the full sequence of the novel coronavirus genome and made the data available to researchers worldwide. This novel coronavirus was later

Alfonso Scarpa

alfonsoscarpa@yahoo.it

Extended author information available on the last page of the article designated as Severe Acute Respiratory Syndrome Coronavirus 2 (SARS-CoV-2) and the disease named as Coronavirus disease 2019 (COVID-19) in February 2020 by the World Health Organization (WHO) [3, 4]. Thus far, SARSCoV-2 had spread worldwide and the WHO, on March 11, declared COVID-19 a pandemic with the sustained risk of further global spread [5-7].

Currently, the human-to-human transmission is believed to occur through respiratory aerosol, droplets from coughing and sneezing, and indirect transmission. Close contacts with affected subjects can thus lead the spread of COVID-19 to growth exponentially in a short time, especially in the presence of milder symptomatic or asymptomatic people. The use of precautionary hygiene measures and the early identification of suspected subjects, including those with atypical presentations, are crucial to prevent cross-infections. The clinical features of COVID-19 largely resemble those observed for SARS-CoV and MERS-CoV infections: the 
most recurrent traits are fever, dry cough, dyspnoea, and bilateral ground-glass opacities on chest computed tomography scans, while fewer patients present with intestinal signs and symptoms $[8,9]$.

In such a scenario, there is a growing body of reports of paucisymptomatic or clinically atypical cases of COVID-19, who represent potential "silent carriers" of infection. This is even more relevant for healthcare professionals, at elevated risk of exposure, who may be at the same time victims of and unknowing responsible for new cases of disease [10, $11]$.

In this perspective study, we aimed at investigating the atypical or paucisymptomatic presentation of COVID-19 by the presence of sudden olfactory loss (SOL) [12-18], making hypotheses about the pathophysiological mechanism of SOL in COVID-19. At the same time, we investigated whether this symptom can represent an early marker of the disease and whether it can be used to identify otherwise asymptomatic subjects.

\section{Materials and methods}

We developed a pilot survey named "Sudden Olfactory Loss and COVID-19". To gather data from a geographically dispersed sample in a short time, we used an Internet-based 15-item questionnaire, posted on a social media closed group of Italian general practitioners. Reports were collected during March 2020.

The aim of this survey was to anonymously collect details from patients complaining of SOL with regards to the assumed correlation with COVID-19 infection, similarly to studies performed in other countries [19].

The survey was administered to general practitioners who evaluated subjects complaining olfactory impairment in the study period. These patients were selected on the basis of sudden onset of the olfactory disturbance during the COVID-19 outbreak in Italy. The main exclusion criterion was a positive anamnesis for previous olfactory alterations.

Questionnaire was designed and administered using Google Forms; responses were collected in an online Excel spreadsheet; questionnaire took $<10 \mathrm{~min}$ to complete. Access to the online spreadsheet was limited to the principal investigator. Questions were mostly close ended. In this pilot phase, we added a final open-ended question aiming to identify further key responses. Informed consent to the use of anonymised data was provided in the questionnaire.

The questionnaire was composed of five sections: (a) respondents' workplace, age, and sex of the patient; (b) general information about the risk of exposure to COVID-19, asking to specify if the patient is a healthcare professional; (c) clinical information: onset of symptoms, grade of olfactory loss (OL) with three subjective levels (mild, moderate, and severe/complete), presence or absence of: ageusia, hypogeusia and/or dysgeusia gathered together under the name of "taste symptoms"; nasal discharge and/or congestion, other accompanying symptoms (e.g., fever, fatigue, dry cough, dyspnoea, and myalgia), comorbidities and complications; d) execution and results of nasopharyngeal (NP)/oropharyngeal (OP) swab; e) short description about the clinical case.

Data were analysed using Statistical Packages for Social Sciences (SPSS), version 26 (SPSS Inc., Chicago, IL, USA).

\section{Results}

From March 11th to March 31st 2020, we collected 180 unique responses (180 patients) from 100 Italian general practitioners. Three Italian practitioners reported some cases also from European hospitals, where they currently work. Geographic distribution is shown in Fig. 1. At the time of the study, Lombardy, Emilia-Romagna, and Piedmont were the most affected regions by COVID-19 outbreak.

SOL occurred in 104 (57.8\%) females and 76 (42.2\%) males, with a female-to-male ratio of 1.37 . The mean age was 39.6 years $(\mathrm{SD} \pm 10.9$; median 37.0$)$ with a range of 21-82 years. Half of the population was between 30 and 40 years $(47.2 \%, n=85)$, while the less represented group was over 59 years old (5.5\%) (Table 1). Among the recruited patients, 115 (63.9\%) had contact with other suspected or confirmed COVID-19 cases and 84 (46.7\%) were healthcare professionals.

\section{Olfactory dysfunction}

Olfactory dysfunction was categorized into three subjective levels of severity: $65.6 \%$ of patients $(n=118)$ complained about severe/total loss (severe hyposmia/anosmia), whereas the others were moderately $(27.2 \%, n=49)$ or slightly $(7.2 \%$, $n=13$ ) affected (hyposmia), respectively. The majority of cases $(92.2 \%, n=166)$ presented olfactory dysfunction in combination with taste disturbances (Fig. 2).

Mixed responses were collected on the duration of olfactory impairment, mostly reporting the persistence of the $\mathrm{OL}$ at the time of the completion of questionnaire, or a slight improvement within 7-20 days. Only 11 subjects experienced a complete remission of olfactory symptoms that lasted between 2 and 10 days.

\section{Accompanying symptoms}

The accompanying symptoms are summarized in Table 1 . The mean time of SOL onset before or after the first typical COVID-19 symptom (fever, dry cough, and dyspnoea) was 2.4 days $(\mathrm{SD} \pm 2.7)$; anosmia/hyposmia occurred as the first symptom in $46.7 \%$ of cases, as sole symptom in $16.7 \%$ of 


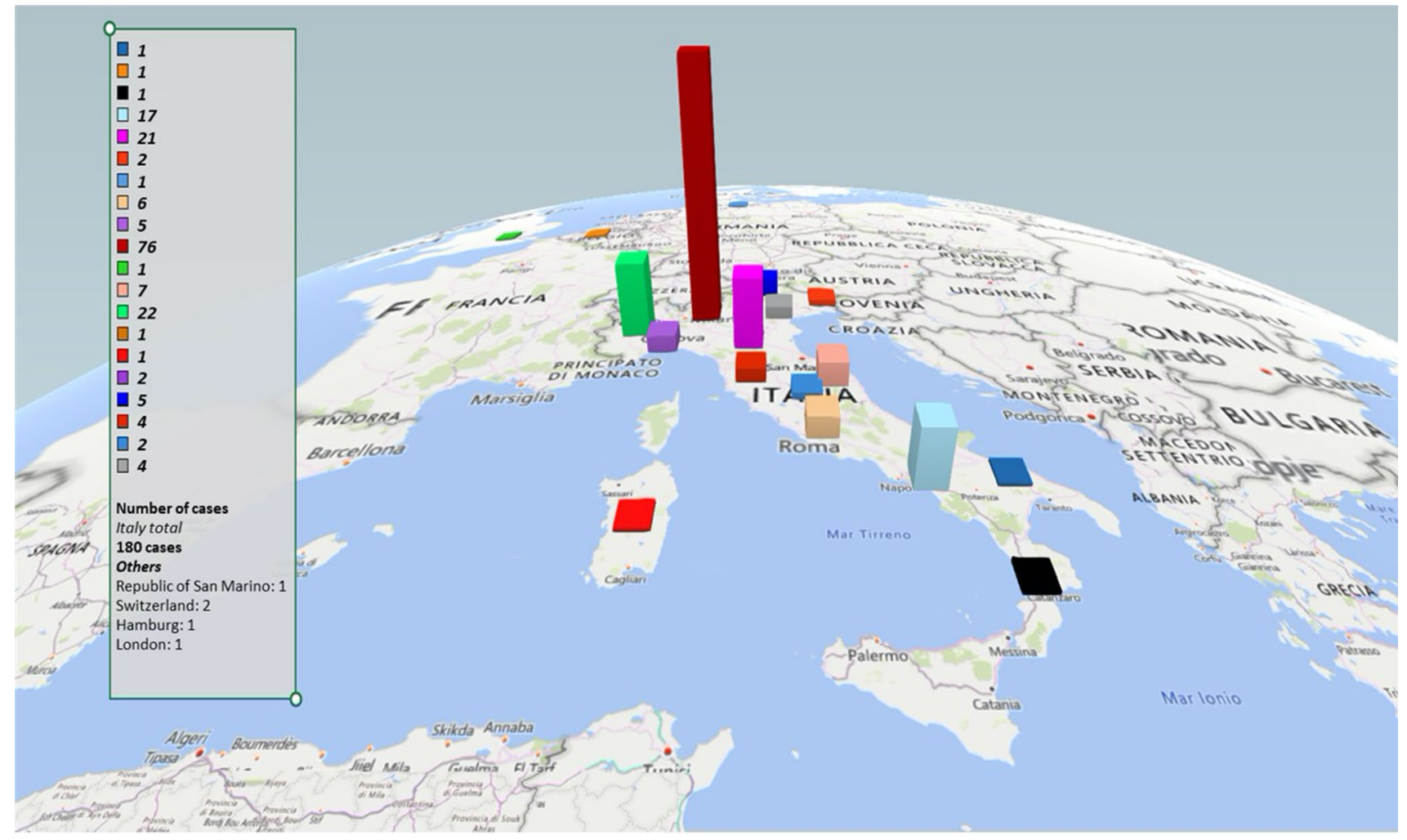

Fig. 1 Geographic distribution of sudden olfactory loss cases across Italy, by region, from March 11th to March 31 st, 2020

cases or in association with other clinical manifestations in $31.2 \%$ of patients.

Analysing the relationship with the fever, in $45.5 \%$ of cases, SOL occurred within 7 days of fever onset; in $40 \%$, it was present without fever; in $14.4 \%$, there was a contemporary appearance. In our cases, fever never followed anosmia. Most of the patients showed a low-grade fever $\left(37-37.5^{\circ} \mathrm{C}\right)$ (Table 1).

SOL occurred without discharge and/or nasal congestion in $117(65.0 \%)$ subjects.

Notably, no accompanying symptom were reported in 30 (16.7\%) cases, only one in $24(13.3 \%)$ cases, 2 or 3 in 82 ( $45.5 \%)$ cases, and more than 4 symptoms in 44 (24.4\%) cases.

Thirty-seven patients $(20.5 \%)$ had coexisting medical conditions. Interstitial pneumonia affected 7 patients (Table 1).

\section{Confirmed COVID-19}

NP/OP swabs for SARS-CoV-2 testing were made in 29 (16.1\%) subjects (Fig. 3). The other patients did not meet screening criteria for swab test. Twenty-six patients (89.6\%) tested positive, four of which without history of COVID19 contacts (15.4\%). The symptoms timeline is described in Fig. 4. Twelve subjects were apyretic (46.1\%). Notably, among the COVID-19 confirmed cases, SOL occurred in the initial phase, as the only symptom, in 5 patients (19.2\%).

Interstitial pneumonia due to SARS-CoV-2 was described in five confirmed cases. A 57-year-old female showed moderated SOL and taste complaints with common cold as the only symptoms during the week before clinical presentation of interstitial pneumonia.

\section{Discussion}

The nasal mucosa has a high relative permeability, thin endothelial membrane, and reasonable surface area for absorption of small molecules, as well as macromolecules such as proteins and peptides, nucleotides, viruses, and even stem cells. Intranasal delivery is emerging as a reliable method to reach Central Nervous System (CNS) by-passing the blood-brain barrier for a wide range of agents, from small molecules like drugs, to large elements such as viral vectors, growth factors, and stem cells [20, 21]. The inhaled microorganisms and particles pass first through the nasal cavity, which is largely covered by the respiratory epithelium and mainly contains olfactory sensory neurons, which have cilia exposed to the environment, allowing contact with particles. Each olfactory receptor neuron projects a dendrite into the nasal cavity on the apical side, and on the basal 
Table 1 Baseline features of patients affected by sudden olfactory loss

\begin{tabular}{|c|c|}
\hline \multirow{3}{*}{ Age, mean (DS), median (range) } & Years \\
\hline & $\begin{array}{l}39.6( \pm 10.9) \\
37.0(21-82)\end{array}$ \\
\hline & No. $(\%)$ \\
\hline \multicolumn{2}{|l|}{ Sex } \\
\hline Female & $104(57.8)$ \\
\hline Male & $76(42.2)$ \\
\hline $\mathrm{F}: \mathrm{M}$ ratio & 1.37 \\
\hline Health care professionals & $84(46.7)$ \\
\hline \multicolumn{2}{|l|}{ Comorbidities } \\
\hline Ca rdiovascular disease & $9(5.0)$ \\
\hline Chronic tireopathy & $6(3.3)$ \\
\hline Immunological disorders & $5(2.8)$ \\
\hline Malignancy & $4(2.2)$ \\
\hline Respiratory disease & $4(2.2)$ \\
\hline Gastrointestinal disease & $3(1.7)$ \\
\hline Genetic disease & $3(1.7)$ \\
\hline Obesity & $1(0.5)$ \\
\hline Genitourinary disorders & $1(0.5)$ \\
\hline Chronic rhinosinusitis & $1(0.5)$ \\
\hline \multicolumn{2}{|l|}{ Sign and symptoms } \\
\hline Fever, ${ }^{\circ} \mathrm{C}$ & $108(60.0)$ \\
\hline$>37<37.5$ & $50(27.8)$ \\
\hline$>37.5<38$ & $31(17.2)$ \\
\hline$>38<38.5$ & $14(8.7)$ \\
\hline$>38.5$ & $13(7.2)$ \\
\hline Fatigue & $88(48.9)$ \\
\hline Dry cough & $85(47.2)$ \\
\hline Myalgia & $73(40.5)$ \\
\hline Nasal discharge/obstruction & $63(35.0)$ \\
\hline Headache & $28(15.5)$ \\
\hline Dyspnea & $15(8.3)$ \\
\hline Pharyngalgia & $14(7.8)$ \\
\hline Diarrhoea & $12(6.7)$ \\
\hline Conjunctivities & $10(5.5)$ \\
\hline Nausea/appetite loss & $10(5.5)$ \\
\hline Chest pain & $2(1.1)$ \\
\hline Burning tongue sensation & $2(1.1)$ \\
\hline Phantosmia & $2(1.1)$ \\
\hline Dizziness & $2(1.1)$ \\
\hline \multicolumn{2}{|l|}{ Complications } \\
\hline Interstitial pneumonia & $7(3.9)$ \\
\hline Total sample & $180(100.0)$ \\
\hline
\end{tabular}

side extends its axon through the cribriform plate into the olfactory bulb (OB) of the brain. The axons of the olfactory neurons are a gate to the $\mathrm{OB}$ and provide a direct pathway to the CNS. Some viruses, like Influenza and Herpes simplex, exploit this olfactory pathway to access the $\mathrm{OB}$, from which

\section{Subjective alteration of olfactory and gustatory functions}

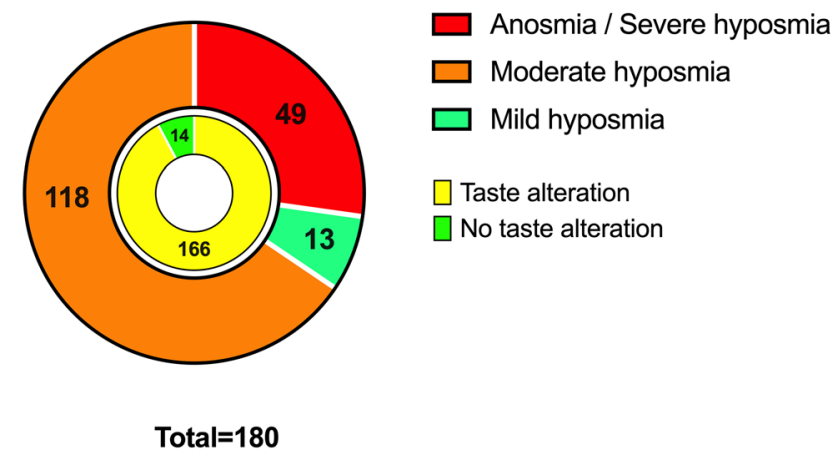

Fig. 2 The impact of olfactory impairment and association with taste symptoms

\section{Nasal / oropharyngeal swab for COVID-19}

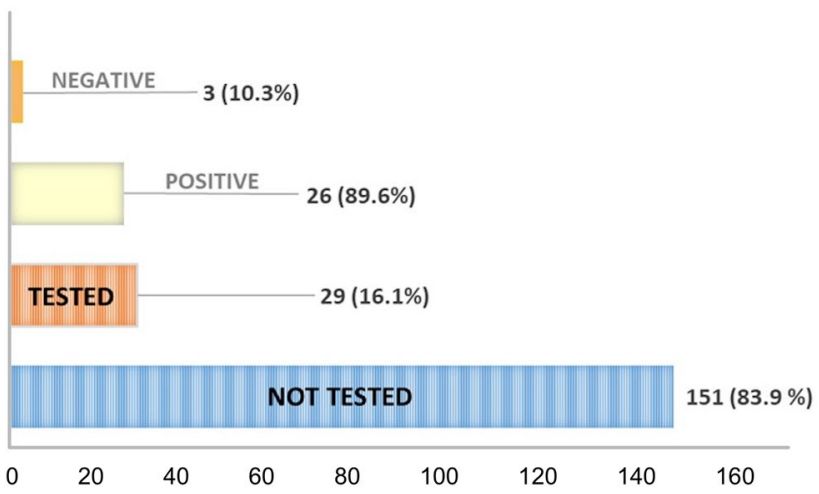

Fig. 3 Results of screening testing for SARS-CoV-2

they can spread to other brain regions, as described in various animal models of infection [22].

\section{Pathophysiological explanations of olfactory impairment in COVID-19}

Neurotropic and neuro-invasive capabilities for several coronavirus $(\mathrm{CoV})$ strains have been described in their hosts, including humans. However, the capacity of $\mathrm{CoV}$ to infect the CNS in humans is still unclear, and mainly based on the detection of viral RNA [8]. A route for neuroinvasion is the transport through olfactory neurons [23]. The olfactory nerve is in communication with the nasal epithelium and the olfactory bulb, providing a unique gateway to the CNS [8]. The previous studies have shown the ability of SARS-CoV to invade brain mainly via the olfactory nerve [20, 23, 24], and thereafter rapidly spread to some specific brain areas, including thalamus and brainstem, causing neuronal death 
Timeline of onset symptoms in COVID-19 patients

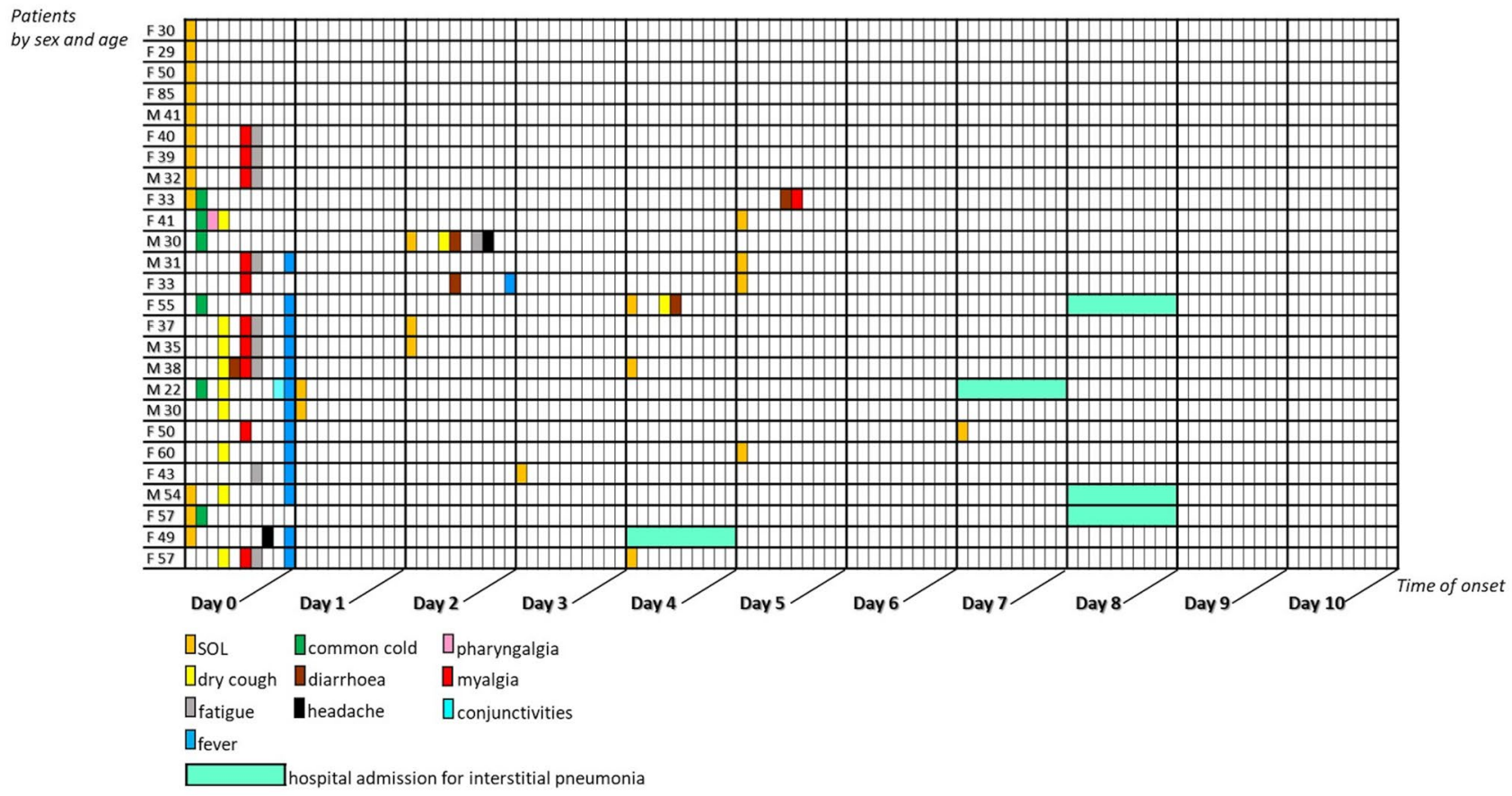

Fig. 4 Symptoms timeline in COVID-19 confirmed patients: case series of 26 subjects evaluated from March 11th to March 31st, 2020

in transgenic mice [20]. This localization could suggest an involvement of solitary tract and ambiguous nuclei, both playing a key role in the regulation of respiratory mechanisms $[24,25]$. The progression of the COVID-19 virus to the brain via the cribriform plate, close to the olfactory bulb, can be an additional pathway that could enable the virus to reach and affect the brain. Huang et al. reported that some patients infected with SARS-CoV-2 showed neurologic signs such as headache (about $8 \%$ ), nausea, and vomiting (1\%) [9]. Additionally, findings such as an altered sense of smell or hyposmia in uncomplicated early stage COVID-19 patients should be investigated thoroughly for CNS involvement [22]. The neuroinvasive propensity has been demonstrated as a common feature of $\mathrm{CoV}$, and, due to the similarity between SARS-CoV and SARS-CoV-2, it is plausible that SARS-CoV-2 possesses a similar potential $[25,26]$.

A further hypothesis on nasal involvement considers tear drainage: the virus may enter the tears through droplets, which pass through the nasolacrimal ducts and then into the respiratory tract [23]. The propagation of the virus particle through the olfactory route follows the mechanisms already seen in several viruses. Furthermore, the identification of 13 different sialic acids in mouse brain, including the olfactory bulbs [27] as well as other tissues, together with the ability of CoV OC43 to interact with 5- $\mathrm{N}$-acetyl-9-0-acetyl neuraminic acid via hemagglutinin-esterase surface glycoprotein $[28,29]$ and the spike glycoprotein [30], may suggest sialic acids as a potential mechanism of entry of SARS-CoV-2 in the CNS.

\section{Association between olfactory impairment and COVID-19}

The available pathophysiological basis supports the association between SOL and COVID-19. Our results also demonstrated the exact geographical coincidence between the distribution of SOL cases and COVID-19 cases. In fact, the territories affected the most by the infection at the time of the investigation coincide with the areas where SOL has been reported the most. In our study, the age distribution of SOL, regardless of its subjective severity, indicated that the symptom is more present in the population aged between 30 and 40 years, as opposed to the major epidemiologic studies that reports the highest estimates in the elderly [31]. Moreover, olfactory impairment is generally unrecognized, because it appears gradually, and self-reports of smell disturbance underestimate the levels of dysfunction detected by quantitative tests [32]. In this perspective, it is striking that in our study, the onset of olfactory dysfunction was not gradual but sudden, with patients being fully aware of this symptom.

In our sample, most patients with complete OL also reported taste alteration. Based on our observations, the taste disorder appears to be likely secondary to the olfactory disorder rather than support the hypothesis of a distinct 
transmission pathway of the virus to the CNS via the lingual nerve [24].

The anamnestic data are particularly important for the demonstration of the correlation of SOL with COVID-19. In our study, $63.9 \%$ of patients had documented exposure to COVID-19 affected subjects. Unfortunately, the confirmation of positivity is only available for a small part of the study population (14.4\%), as the criteria for the screening procedure with a swab did not match the characteristics of most of our patients. Nevertheless, it is possible to deduce this correlation from the frequent association with other typical symptoms of COVID-19, and from comparison with the percentage of patients tested positive (89.6\%), which makes us believe that the majority of the sample could be affected.

It is interesting to note that fever, the symptom most frequently used for COVID-19 screening, is present in some studies in less than $50 \%$ of subjects, at least in the initial stages of the disease, although fever developed in $88.7 \%$ of cases during hospitalization [33]. This undermines the validity of fever as a screening marker for COVID-19, since it may fail to identify subjects in the early stages of the disease. This hypothesis is confirmed in our sample, in which fever, albeit still the most frequent symptom, was present only in $60 \%$ of SOL subjects. In particular, SOL was the only symptom in five (19.2\%) of the cases confirmed by positive swab test.

Moreover, the analysis of the association between fever and OL revealed that in $40 \%$ of cases, OL was present in the absence of fever, and in $14.4 \%$ of cases, there was a contemporary appearance of the two symptoms, while fever never followed anosmia. Therefore, using fever as a screening tool may result ineffective in the initial stages of the disease that represent those with the highest viral load and with the greater risk to spread infection. In fact, patients with COVID-19 appear to have the highest viral load near presentation, which could account for the fast-spreading nature of this epidemic [34]. In the confirmed positive cases of our sample, fever was absent in $46.1 \%$ of subjects, and not considering SOL would have led to losing nearly $20 \%$ of the subjects. These subjects were under the age of 50, therefore those with more intense social/work activity and therefore at greater risk of spreading the virus.

This finding emphasises the importance of stringent infection control. Introducing OL together with fever could also greatly increase the sensitivity of a clinical screening tool for COVID-19.

In our case history, the appearance of SOL frequently preceded the typical symptoms of COVID-19 or occurred within 2.4 days $( \pm 2.7)$ from the appearance of the other symptoms. The pathophysiological hypotheses of the neuroinvasiveness of this virus would support this finding [24]. Based on a recent epidemiological survey on COVID-19, the median time from the first symptom to dyspnoea was 5 days, to hospital admission was 7 days, and to the intensive care was 8 days [35]. The temporal data reinforce the importance of considering SOL as an early marker of infection, until proven otherwise.

Finally, among the recruited patients, 84 (46.7\%) were healthcare professionals: our data confirm that their risk of exposure is extremely high, especially in the absence of adequate individual protection devices and in cases without full-blown symptoms.

\section{Conclusion}

Our data suggest that subjects with SOL without obstructive nasal conditions should be considered as potential COVID19 cases. SOL could represent a possible early marker to identify asymptomatic subjects and to reduce the spread of the infection. Viral shedding from nasal secretions, sneezing, coughing, and sputum can be continuous up to 6 weeks, which builds concerns that asymptomatic individuals could also transmit the infection for such long time. Therefore, it should be recommended to avoid nasal treatments (i.e., nasal washing, spray, and invasive manoeuvres) that could amplify the virus dissemination.

Our preliminary results provide a basis for subsequent research in the field of clinical heterogeneity of COVID-19 and identify a possible clinical marker to increase the sensitivity of screening procedures and limit the spread of the infection through appropriate prevention programs.

Funding The authors declare that they have no sources of funding.

\section{Compliance with ethical standards}

Conflict of interest The authors declare that they have no conflict of interest.

Research involving human participants and/or animals Not applicable.

Participants The survey was administered to any Italian Practitioner registered to a social media group and evaluated 180 subjects complaining olfactory impairment in the study period, with an Internetbased 15-item questionnaire.

Informed consent A checkbox to provide informed consent to the use of provided data was included in the questionnaire. All participants gave their informed consent to the use of anonymized data provided in the responses to the questionnaire.

\section{References}

1. Zhu H, Wei L, Niu P (2020) The novel coronavirus outbreak in Wuhan, China. Glob Health Res Policy 5:6. https://doi. org/10.1186/s41256-020-00135-6 
2. Zhu N, Zhang D, Wang W, Li X, Yang B, Song J, Zhao X, Huang B, Shi W, Lu R, Niu P, Zhan F, Ma X, Wang D, Xu W, Wu G, Gao GF, Tan W, China Novel Coronavirus I, Research T (2020) A novel coronavirus from patients with pneumonia in China. N Engl J Med 382(8):727-733. https://doi.org/10.1056/NEJMoa2001017

3. Ji W, Wang W, Zhao X, Zai J, Li X (2020) Cross-species transmission of the newly identified coronavirus 2019-nCoV. J Med Virol 92(4):433-440. https://doi.org/10.1002/jmv.25682

4. Sohrabi C, Alsafi Z, O'Neill N, Khan M, Kerwan A, Al-Jabir A, Iosifidis C, Agha R (2020) World Health Organization declares global emergency: a review of the 2019 novel coronavirus (COVID-19). Int J Surg 76:71-76. https://doi.org/10.1016/j. ijsu.2020.02.034

5. Gentile I, Abenavoli L (2020) COVID-19: perspectives on the potential novel global threat. Rev Recent Clin Trials. https://doi. org/10.2174/1574887115999200228100745

6. Cui J, Li F, Shi ZL (2019) Origin and evolution of pathogenic coronaviruses. Nat Rev Microbiol 17(3):181-192. https://doi. org/10.1038/s41579-018-0118-9

7. Woo PC, Lau SK, Chu CM, Chan KH, Tsoi HW, Huang Y, Wong BH, Poon RW, Cai JJ, Luk WK, Poon LL, Wong SS, Guan Y, Peiris JS, Yuen KY (2005) Characterization and complete genome sequence of a novel coronavirus, coronavirus HKU1, from patients with pneumonia. J Virol 79(2):884-895. https://doi.org/10.1128/ JVI.79.2.884-895.2005

8. Wu JT, Leung K, Bushman M, Kishore N, Niehus R, de Salazar PM, Cowling BJ, Lipsitch M, Leung GM (2020) Estimating clinical severity of COVID-19 from the transmission dynamics in Wuhan, China. Nat Med 26(4):506-510. https://doi.org/10.1038/ s41591-020-0822-7

9. Huang C, Wang Y, Li X, Ren L, Zhao J, Hu Y, Zhang L, Fan G, Xu J, Gu X, Cheng Z, Yu T, Xia J, Wei Y, Wu W, Xie X, Yin W, Li H, Liu M, Xiao Y, Gao H, Guo L, Xie J, Wang G, Jiang R, Gao Z, Jin Q, Wang J, Cao B (2020) Clinical features of patients infected with 2019 novel coronavirus in Wuhan, China. Lancet 395(10223):497-506. https://doi.org/10.1016/S0140 $-6736(20) 30183-5$

10. Adams JG, Walls RM (2020) Supporting the health care workforce during the COVID-19 global epidemic. JAMA. https://doi. org/10.1001/jama.2020.3972

11. Ralli M, Greco A, de Vincentiis M (2020) The effects of the COVID-19/SARS-CoV-2 pandemic outbreak on otolaryngology activity in Italy. Ear Nose Throat J. https://doi.org/10.1177/01455 61320923893

12. Gourtsoyannis J (2020) COVID-19: possible reasons for the increased prevalence of olfactory and gustatory dysfunction observed in European studies. Clin Infect Dis. https://doi. org/10.1093/cid/ciaa685

13. Lechien JR, Chiesa-Estomba CM, Place S, Van Laethem Y, Cabaraux P, Mat Q, Huet K, Plzak J, Horoi M, Hans S, Barillari MR, Cammaroto G, Fakhry N, Martiny D, Ayad T, Jouffe L, Hopkins C, Saussez S, YO-IFOS C-TFo (2020) Clinical and epidemiological characteristics of 1,420 european patients with mild-to-moderate coronavirus disease 2019. J Int Med. https://doi.org/10.1111/ joim. 13089

14. Ralli M, Di Stadio A, Greco A, de Vincentiis M, Polimeni A (2020) Defining the burden of olfactory dysfunction in COVID-19 patients. Eur Rev Med Pharmacol Sci 24(7):3440-3441. https:// doi.org/10.26355/eurrev_202004_20797

15. Lechien JR, Hsieh J, Barillari MR, Cammaroto G, Hans S, Chiesa-Estomba CM, Saussez S (2020) Patient-reported outcome questionnaires for the evaluation of olfactory and gustatory dysfunctions in COVID-19. Eur Arch Otorhinolaryngol. https://doi. org/10.1007/s00405-020-06083-8

16. Boscolo-Rizzo P, Borsetto D, Spinato G, Fabbris C, Menegaldo A, Gaudioso P, Nicolai P, Tirelli G, Da Mosto MC, Rigoli R,
Polesel J, Hopkins C (2020) New onset of loss of smell or taste in household contacts of home-isolated SARS-CoV-2-positive subjects. Eur Arch Otorhinolaryngol. https://doi.org/10.1007/ s00405-020-06066-9

17. Printza A, Constantinidis J (2020) The role of self-reported smell and taste disorders in suspected COVID19. Eur Arch Otorhinolaryngol. https://doi.org/10.1007/s00405-020-06069-6

18. Speth MM, Singer-Cornelius T, Obere M, Gengler I, Brockmeier SJ, Sedaghat AR (2020) Olfactory dysfunction and sinonasal symptomatology in COVID-19: prevalence, severity, timing, and associated characteristics. Otolaryngol Head Neck Surg. https://doi.org/10.1177/0194599820929185

19. Panuganti BA, Jafari A, MacDonald B, DeConde AS (2020) Predicting COVID-19 incidence using anosmia and other COVID-19 symptomatology: preliminary analysis using google and twitter. Otolaryngol Head Neck Surg. https://doi. org/10.1177/0194599820932128

20. Mittal D, Ali A, Md S, Baboota S, Sahni JK, Ali J (2014) Insights into direct nose to brain delivery: current status and future perspective. Drug Deliv 21(2):75-86. https://doi. org/10.3109/10717544.2013.838713

21. Bilinska K, Jakubowska P, Von Bartheld CS, Butowt R (2020) Expression of the SARS-CoV-2 entry proteins, ACE2 and TMPRSS2, in cells of the olfactory epithelium: identification of cell types and trends with age. ACS Chem Neurosci 11(11):1555-1562. https://doi.org/10.1021/acschemneu ro.0c00210

22. Bryche B, Fretaud M, Saint-Albin Deliot A, Galloux M, Sedano L, Langevin C, Descamps D, Rameix-Welti MA, Eleouet JF, Le Goffic R, Meunier N (2019) Respiratory syncytial virus tropism for olfactory sensory neurons in mice. J Neurochem. https://doi. org/10.1111/jnc. 14936

23. van Riel D, Verdijk R, Kuiken T (2015) The olfactory nerve: a shortcut for influenza and other viral diseases into the central nervous system. J Pathol 235(2):277-287. https://doi.org/10.1002/ path. 4461

24. Hori S, Narumi Y, Marukawa T, Tomoda K, Katayama K, Tanaka T, Tokunaga K, Yoshioka H, Kuroda C (1984) A new intravenous liposoluble contrast material for computed tomography of the liver. Experimental study of iodized emulsion in rabbits. Nihon Igaku Hoshasen Gakkai Zasshi 44(7):988-991

25. Li YC, Bai WZ, Hashikawa T (2020) The neuroinvasive potential of SARS-CoV2 may play a role in the respiratory failure of COVID-19 patients. J Med Virol. https://doi.org/10.1002/ jmv. 25728

26. Bigiani A (2020) Gustatory dysfunctions in COVID-19 patients: possible involvement of taste renin-angiotensin system (RAS). Eur Arch Otorhinolaryngol. https://doi.org/10.1007/s00405-02006054-Z

27. Rinninger A, Richet C, Pons A, Kohla G, Schauer R, Bauer HC, Zanetta JP, Vlasak R (2006) Localisation and distribution of $\mathrm{O}$-acetylated $\mathrm{N}$-acetylneuraminic acids, the endogenous substrates of the hemagglutinin-esterases of murine coronaviruses, in mouse tissue. Glycoconj J 23(1-2):73-84. https://doi.org/10.1007/s1071 9-006-5439-7

28. Vlasak R, Luytjes W, Leider J, Spaan W, Palese P (1988) The E3 protein of bovine coronavirus is a receptor-destroying enzyme with acetylesterase activity. J Virol 62(12):4686-4690

29. Vlasak R, Luytjes W, Spaan W, Palese P (1988) Human and bovine coronaviruses recognize sialic acid-containing receptors similar to those of influenza $\mathrm{C}$ viruses. Proc Natl Acad Sci USA 85(12):4526-4529. https://doi.org/10.1073/pnas.85.12.4526

30. Tecnology in the service of the patient (1978). Tijdschr Ziekenverpl 31 (19):879-880

31. Boesveldt S, Postma EM, Boak D, Welge-Luessen A, Schopf V, Mainland JD, Martens J, Ngai J, Duffy VB (2017) Anosmia-a 
clinical review. Chem Senses 42(7):513-523. https://doi. org/10.1093/chemse/bjx025

32. Doty RL (2019) Epidemiology of smell and taste dysfunction. Handb Clin Neurol 164:3-13. https://doi.org/10.1016/B978-0444-63855-7.00001-0

33. Guan WJ, Ni ZY, Hu Y, Liang WH, Ou CQ, He JX, Liu L, Shan H, Lei CL, Hui DSC, Du B, Li LJ, Zeng G, Yuen KY, Chen RC, Tang CL, Wang T, Chen PY, Xiang J, Li SY, Wang JL, Liang ZJ, Peng YX, Wei L, Liu Y, Hu YH, Peng P, Wang JM, Liu JY, Chen Z, Li G, Zheng ZJ, Qiu SQ, Luo J, Ye CJ, Zhu SY, Zhong NS, China Medical Treatment Expert Group for C (2020) Clinical characteristics of coronavirus disease 2019 in China. N Engl J Med 382(18):1708-1720. https://doi.org/10.1056/NEJMoa2002 032

34. To KK, Tsang OT, Leung WS, Tam AR, Wu TC, Lung DC, Yip CC, Cai JP, Chan JM, Chik TS, Lau DP, Choi CY, Chen LL, Chan WM, Chan KH, Ip JD, Ng AC, Poon RW, Luo CT, Cheng VC,
Chan JF, Hung IF, Chen Z, Chen H, Yuen KY (2020) Temporal profiles of viral load in posterior oropharyngeal saliva samples and serum antibody responses during infection by SARS-CoV-2: an observational cohort study. Lancet Infect Dis 20(5):565-574. https://doi.org/10.1016/S1473-3099(20)30196-1

35. Wang D, Hu B, Hu C, Zhu F, Liu X, Zhang J, Wang B, Xiang H, Cheng Z, Xiong Y, Zhao Y, Li Y, Wang X, Peng Z (2020) Clinical characteristics of 138 hospitalized patients with 2019 novel coronavirus-infected pneumonia in Wuhan, China. JAMA. https ://doi.org/10.1001/jama.2020.1585

Publisher's Note Springer Nature remains neutral with regard to jurisdictional claims in published maps and institutional affiliations.

\section{Affiliations}

\section{Lucrezia Spadera $^{1} \cdot$ Pasquale Viola $^{2} \cdot$ Davide Pisani $^{2} \cdot$ Alfonso Scarpa $^{3}$ (1) - Donatella Malanga ${ }^{4,5}$. Gerardo Sorrentino ${ }^{1}$. Enrico Madini ${ }^{6}$. Carla Laria ${ }^{7} \cdot$ Teodoro Aragona $^{8}$. Gianluca Leopardi ${ }^{9}$. Giandomenico Maggiore ${ }^{10} \cdot$ Marco Ciriolo $^{2} \cdot$ Luigi Boccuto $^{11,12} \cdot$ Raffaella Pizzolato $^{13}$. Ludovico Abenavoli $^{14}$. Claudia Cassandro ${ }^{15} \cdot$ Massimo Ralli $^{16} \cdot$ Ettore Cassandro $^{3} \cdot$ Giuseppe Chiarella $^{2}$}

Lucrezia Spadera

lucrezia.spadera@libero.it

Pasquale Viola

pasqualeviola@unicz.it

Davide Pisani

davidepisani@gmail.com

Donatella Malanga

malanga@unicz.it

Gerardo Sorrentino

gersorre@gmail.com

Enrico Madini

maddoc@fastpiu.it

Carla Laria

carla.laria@unina.it

Teodoro Aragona

teodoroaragona@yahoo.it

Gianluca Leopardi

gianluca.leopardi@gmail.com

Giandomenico Maggiore

maggiore2@virgilio.it

Marco Ciriolo

marcociriolo77@gmail.com

Luigi Boccuto

lboccuto@ggc.org

Raffaella Pizzolato

raffaella.pizzolato@gmail.com

Ludovico Abenavoli

1.abenavoli@unicz.it

Claudia Cassandro

claudiacassandro@inwind.it
Massimo Ralli

massimo.ralli@uniroma1.it

Ettore Cassandro

ecassandro@unisa.it

Giuseppe Chiarella

chiarella@unicz.it

1 Otolaryngology, San Leonardo Hospital, Castellammare di Stabia, Naples, Italy

2 Unit of Audiology, Department of Experimental and Clinical Medicine, Regional Centre for Cochlear Implants and ENT Diseases, Magna Graecia University, Catanzaro, Italy

3 Department of Medicine and Surgery, University of Salerno, Salerno, Italy

4 Laboratory of Molecular Oncology, Department of Experimental and Clinical Medicine, Magna Graecia University, Catanzaro, Italy

5 Interdepartmental Center of Services (CIS), University Magna Graecia of Catanzaro, Catanzaro, Italy

6 General Practioner, Cremona, Italy

7 Unit of Audiology, Department of Neurosciences, Reproductives and Odontostomatologic Sciences, University of Naples "Federico II", Naples, Italy

8 Otolaryngology, A.O.U. Ospedali Riuniti, Ancona, Italy

9 Otolaryngology, S. Giuseppe Hospital, Empoli, Florence, Italy

10 Otolaryngology, Head and Neck Surgery, A.O.U. Careggi, Florence, Italy

11 Greenwood Genetic Center, Greenwood, SC, USA

12 Clemson University, Clemson, SC, USA

13 Department of Neurology, University of Massachusetts, Medical School, Worcester, MA, USA 
14 Department of Health Sciences, University Magna Graecia, Catanzaro, Italy

15 Surgical Sciences Department, University of Turin, Turin, Italy
16 Department of Sense Organs, Sapienza University of Rome, Rome, Italy 